\title{
An observational study for appraisal of clinical outcome and risk of mother-to-child SARS-CoV-2 transmission in neonates provided the benefits of mothers' own milk
}

\author{
Priyanka Gupta ${ }^{1}$ (1) $\cdot$ Vijay Pratap Khatana ${ }^{1} \cdot$ Rashmie Prabha $^{1} \cdot$ Inderkant Jha ${ }^{1} \cdot$ Mitasha Singh $^{2}$. \\ Anil Kumar Pandey ${ }^{3}$. Ashima Kesri ${ }^{4}$
}

Received: 26 April 2021 / Revised: 6 July 2021 / Accepted: 9 July 2021 / Published online: 11 August 2021

(c) The Author(s), under exclusive licence to Springer-Verlag GmbH Germany, part of Springer Nature 2021

\begin{abstract}
This observational study done during April-December 2020 at a tertiary-care hospital in Haryana (India) enrolled 152 SARS-CoV-2-exposed neonates. Among them, 150 neonates had perinatal SARS-CoV-2 exposure and 2 neonates had late postnatal exposure. Stable infant-mother dyads were roomed-in with precautions to support breastfeeding. Nasopharyngeal swabs collected from neonates were tested for SARS-CoV-2 by reverse transcriptase-polymerase chain reaction (RT-PCR) test. There was a high incidence of prematurity (23\%), low birth weight (31\%), intrauterine fetal distress (16\%), perinatal asphyxia (6\%), admission to neonatal intensive care unit (24\%), and mortality (1.3\%) among neonates with perinatal SARS$\mathrm{CoV}-2$ exposure. In this sub-group, 20 neonates tested positive for SARS-CoV-2 in nasopharyngeal swab sample(s). A recent official publication by the World Health Organization emphasizes that the perinatal SARS-CoV-2-exposed neonates found RT-PCR positive once in upper respiratory (non-sterile) sample must document viral persistence in another non-sterile sample for confirmation of mother-to-child virus transmission. With this approach, only one neonate was confirmed intrapartum transmission. A telephonic follow-up in discharged neonates at 1 month of age or 1 month postexposure recorded them all to be asymptomatic and doing well.

Conclusion: Neonates with perinatal SARS-CoV-2 exposure constitute a high-risk group and it is not uncommon to get a positive RT-PCR report in upper respiratory sample(s) from these babies. Majority of them do not demonstrate viral persistence. Clinical outcomes are favorable in breastfed infants roomed-in with their asymptomatic-mild symptomatic SARSCoV-2-infected mothers following appropriate safety protocols.
\end{abstract}

\section{What is Known:}

- Neonates with perinatal exposure suffer a high burden of morbidities and mortality.

- Still, an uncertainty exists about rooming-in and breastfeeding among neonates born to SARS-CoV-2 positive mothers.

What is New:

- With the policy of mother-infant rooming-in and supporting breastfeeding, none of the neonate suffered clinical illness compatible with postnatal SARS-CoV-2 transmission and infection.

- Around $13 \%$ perinatal exposed neonates demonstrated SARS-CoV-2 RNA in nasopharyngeal swab samples but the majority of them did not demonstrate viral persistence.

Keywords Breastfeeding $\cdot$ COVID-19 $\cdot$ Mother-to-child transmission · Outcome $\cdot$ Rooming-in $\cdot$ SARS-CoV-2

\begin{tabular}{|c|c|c|c|}
\hline \multicolumn{2}{|c|}{ Abbreviations } & \multirow{2}{*}{$\begin{array}{l}\text { EBM } \\
\text { ESR }\end{array}$} & \multirow{2}{*}{$\begin{array}{l}\text { Expressed breast milk } \\
\text { Erythrocyte sedimentation rate }\end{array}$} \\
\hline COVID-19 & Coronavirus disease of 2019 & & \\
\hline \multirow[t]{2}{*}{ CTG } & Cardiotocography & NICU & Neonatal intensive care unit \\
\hline & & NP & Nasopharyngeal \\
\hline \multicolumn{2}{|c|}{ Communicated by Daniele De Luca } & $\begin{array}{l}\text { PPV } \\
\text { RNA }\end{array}$ & $\begin{array}{l}\text { Positive pressure ventilation } \\
\text { Ribonucleic acid }\end{array}$ \\
\hline \multicolumn{2}{|c|}{$\begin{array}{l}\text { Priyanka Gupta } \\
\text { drpriyankaguptakapil@gmail.com }\end{array}$} & RT-PCR & $\begin{array}{l}\text { Reverse transcription polymerase chain } \\
\text { reaction }\end{array}$ \\
\hline
\end{tabular}

Extended author information available on the last page of the article 
SARS-CoV-2 Severe acute respiratory syndrome coronavirus-2

WHO

World Health Organization

\section{Introduction}

Few studies have demonstrated the presence of virus ribonucleic acid (RNA) material in breast milk samples collected from the mothers infected with SARS-CoV-2 but this seems unlikely to be a mode of mother-to-child transmission because no replication-competent virus has been detected in breast milk samples till date [1-4]. On the other hand, SARS-CoV-2-specific immunoglobulins in breast milk might be protective against infection and symptomatic-severe disease [5, 6]. Unprotected close contact during breastfeeding and other aspects of baby care is still an important route for postnatal virus transmission without any debate. Majority of national and regional guidelines advocates supporting direct breastfeeding among mothers infected with SARS-CoV-2, very few prohibiting any breast milk, and a few restricting direct breastfeeding but allowing expressed breast milk (EBM) feeding [7]. There had always been an uncertainty over rooming-in neonates with their SARS-CoV-2-infected mothers. Majority of guidelines including that given by academic organizations in India recommends keeping stable mother-infant dyads together but some still suggest their separation for variable periods of time after birth [7-9].

Mother-infant isolation demands a lot of logistic support. On the other hand, one cannot guarantee postnatal contact of neonate with another infected caregiver or hospital staff after separation from their own mother. During the early phase of coronavirus pandemic in India, it was a challenge to let go of norm of breastfeeding in neonates without any conclusive evidence, and thus, we allowed rooming-in stable neonates with their stable SARS-CoV-2-infected mothers following a safety protocol so that the babies could be provided benefits of mother's own milk effectively $[8,9]$. There is limited published data about neonatal outcome and risk of mother-to-child virus transmission following such clinical management protocols. The present study attempts to fill this knowledge gap.

\section{Material and methods}

\section{Study design, setting, and objectives}

This observational study did not interfere with the departmental management protocols and was done with approval of Institutional Ethics Committee between April and December 2020 at Employees State Insurance Corporation Medical
College and Hospital, Faridabad (Haryana, India) which served as a referral center and dedicated COVID-19 hospital during the study period.

\section{Participant eligibility criteria}

All SARS-CoV-2-exposed neonates $(<1$ month age) admitted in the Department of Paediatrics (Neonatology) during the study period were enrolled after informed consent of parent(s). Neonates were defined to have "perinatal SARS-CoV-2 exposure" if born to a mother with confirmed SARS-CoV-2 infection diagnosed 14 days prior to 2 days after childbirth [9-11]. Exposure of neonate to infected mother beyond this time period or a close contact $(<1 \mathrm{~m}$ for $>15 \mathrm{~min}$ or living in the same household) with someone else infected with SARS-CoV-2 was defined as "late postnatal SARS-CoV-2 exposure" (Fig. 1).

\section{Clinical case management}

The mode of delivery was guided by obstetric-fetal assessment, intranatal cardiotocographic (CTG) monitoring, and hemodynamic status of the mother. No mother-infant separation was done in well babies with asymptomatic or mild symptomatic mothers, i.e., those without any shortness of breath or hypoxia. Direct breastfeeding was initiated as early as possible within $1 \mathrm{~h}$ of birth. Mothers were advised to wear a triple-layered surgical mask all the time and being more careful during breastfeeding and handling the neonate. They were advised to change and discard the mask every $6 \mathrm{~h}$. An easy access to soap and water, as well as alcohol-based hand sanitizers, was provided to maintain hand hygiene. Dedicated nurses trained in essential newborn care and lactation management were stationed for constant supervision. Very low birth weight, high risk, and sick neonates were transferred to a designated NICU (neonatal intensive care unit) in the COVID block. During such periods of temporary mother-infant separation, the mothers were encouraged to visit their baby for feeding with EBM and being involved in baby care (like diapering) taking respiratory and hand hygiene precautions. Formula milk was used only when the EBM provided was inadequate known as "partial breastfeeding or mixed feeding."

\section{Screening for SARS-CoV-2 infection in neonates and interpretation of results}

Nasopharyngeal (NP) swabs for detection of SARS-CoV-2 ribonucleic acid (RNA) by reverse transcription-polymerase chain reaction (RT-PCR) test were collected by trained staff or pediatric residents. Three genes of SARS-CoV-2, i.e., E-gene (envelope coding gene), RdRP-gene (RNA-dependent RNA polymerase gene), and $\mathrm{N}$-gene (nucleocapsid 
Total 'SARS-CoV-2 exposed' neonates enrolled in the study: $\mathbf{n ~ - ~} 152$

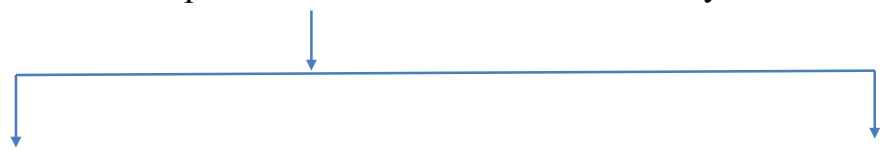

Perinatal exposure (neonates born to RT-PCR confirmed SARS-CoV-2 positive mothers diagnosed near the time of childbirth from 14 days prior to 2 days after birth): $\mathbf{n} \mathbf{- 1 5 0}$



Extramural births: $\mathbf{n} \mathbf{- 1 2}$

Admission at $<\mathbf{2 4}$ hours of age- 4; 24-48 hours of age- 1 ; beyond 48 hours of age- 7

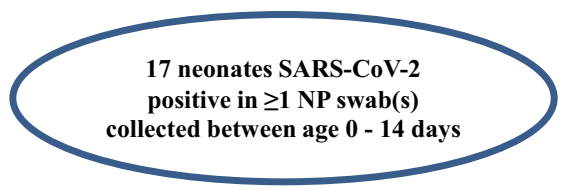

Late postnatal exposure (neonates exposed to RT-PCR confirmed SARS-CoV-2 positive mothers diagnosed $>2$ days after birth): $\mathbf{n}-\mathbf{2}$

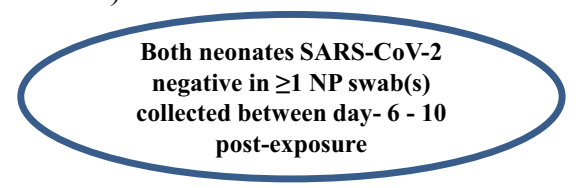

Fig. 1 Characteristics of SARS-CoV-2 exposure and screening among study participants

encoding gene) were tested using Allplex ${ }^{\mathrm{TM}}$ 2019-nCoV Assay kit (Seegene Inc). Cycle threshold $(\mathrm{Ct})$ value $\leq 35$ was considered RT-PCR positive and $>35$ as negative.

With an early discharge policy, first NP swab sample was collected at birth $(<24 \mathrm{~h}$ of age) after drying and initial stabilization among intramural births. Rooming-in and breastfeeding was not postponed for the sake of collection of NP swab sample. First NP swab sampling in extramural neonates and those with late postnatal exposure was done immediately at the time of admission. Second NP swab sample was collected on day 2 (between 24 and $48 \mathrm{~h}$ of life) and the third NP swab sample collected after day 5 by day 14 of life or exposure. Additional NP swab samples were tested in case of any new symptom(s). Examination of placental tissue, amniotic fluid, cord blood, neonatal blood, lower respiratory sample, or stool were not the part of study protocol.

\section{Discharge policy and follow-up}

Asymptomatic or mild-moderate ill SARS-CoV-2-positive neonates (whose symptoms and need of oxygen abate within 3 days) stayed in the hospital for minimum of 10 days and were discharged after documentation of at least one negative RT-PCR report. An early discharge policy was followed among stable mother-infant dyads. Mothers were advised to continue exclusive breastfeeding for 6 months and follow above mentioned COVID-19 safety protocols for at least 2 more weeks. At the time of discharge, she was explained about all danger signs. All neonates were followed-up telephonically at 1 month of age or SARS-CoV-2 exposure by the investigators from neonatology team. They were asked about their general well-being and if they had any concerns such as fever, poor feeding, respiratory symptoms, gastrointestinal symptoms, and/or any healthcare visit since discharge.

\section{Variables recorded}

Demographic details, severity of COVID-19 illness in the mother, medical-obstetric complications, and labor events were recorded. The variables recorded for the neonates were the gestational age and weight at birth, adverse events at the time of birth, details of feeding, morbidities and mortality suffered, and the results of SARS-CoV-2 testing.

\section{Statistical analysis}

Anonymized data was compiled in the Microsoft Excel Software and analyzed by Epi Info Version 7. Descriptive statistics, namely, frequencies, proportions, and mean \pm standard deviation, were applied to summarize the data.

\section{Results}

\section{Participants}

Among 152 SARS-CoV-2-exposed neonates, 138 were intramural births from mothers infected with SARS-CoV-2 at the time of childbirth, 12 were extramural neonates born to SARS-CoV-2-infected mothers and referred from other non-COVID hospitals, and 2 neonates were admitted after 
their mothers were diagnosed with mild COVID-19 illness day 10 and day 12 postpartum (Fig. 1).

\section{Gestational risk factors, severity of COVID-19 in mother, and adverse intranatal events}

Among 150 mothers diagnosed with SARS-CoV-2 infection around the time of childbirth, 50 (33.3\%) were primigravidae, 65 (43.3\%) were second gravidae, and the remaining were gravida $\geq 3$. Their age ranged from 17 to 39 years (mean $\pm \mathrm{SD} ; 26.07 \pm 4.43$ ). Co-morbid medical and/or obstetric complications like anemia, gestational hypertension, diabetes, and oligohydramnios were present in 63 (42\%) mothers. One mother had severe pneumonia requiring respiratory support for 2 days, 15 (10\%) had mild symptoms, and $134(89.3 \%)$ mothers were asymptomatic for SARSCoV-2 infection. Both mothers diagnosed of SARS-CoV-2 infection during postpartum period had mild symptoms. CTG recordings were abnormal in $24(16 \%)$ and amniotic fluid was meconium stained in $29(19.3 \%)$ mothers. Cesarean section was performed for various fetal-maternal indications in $98(65.3 \%)$ mothers.

\section{Clinical outcome in SARS-CoV-2-exposed neonates}

Among 150 neonates with perinatal exposure, the gestational maturity at birth ranged from 29 to 42 weeks (mean $\pm \mathrm{SD}, 37.85 \pm 1.93$ ) and the birth weight ranged from 1100 to $3900 \mathrm{~g}$ (mean $\pm \mathrm{SD}, 2642.57 \pm 503.24)$. There was a high incidence of prematurity (22.7\%), low birth weight (31.3\%), and being small for gestational age (38\%). Total $34(22.7 \%)$ neonates required some assistance for breathing at birth, majority (25/34) responding to initial steps alone. Overall, $9(6 \%)$ neonates suffered perinatal asphyxia (Apgar score $<7$ at $1 \mathrm{~min}$ of age) among which $4(2.7 \%)$ suffered severe perinatal asphyxia (Apgar score $<3$ at $1 \mathrm{~min}$ of age). Some respiratory support was required in $18(12 \%)$ neonates. All neonates on respiratory support could be completely weaned off oxygen within 3 days. There was a high burden of neonatal morbidities and $36(24 \%)$ neonates required NICU care (Table 1).

Two neonates with perinatal SARS-CoV-2 exposure suffered mortality during early neonatal period. One female neonate was born vaginally at 39 weeks with birth weight $2500 \mathrm{~g}$. Her mother was asymptomatic for SARS-COV-2 infection, young 17-year-old, primigravida, and anemic with gestational hypertension. The history of being handled by traditional birth attendant prior to admission posed a risk for neonatal sepsis, though initially this history was concealed by the family. Baby required oro-nasal suction at birth to clear the airway of secretions, no other resuscitation support was required, and the Apgar scores were normal. The initial sepsis screen including total leucocyte count, differential leucocyte count, $\mu \mathrm{ESR}$, peripheral smear findings, and $\mathrm{C}$-reactive protein were normal, and the blood culture was sterile. Baby was roomed-in with her mother and was partial breastfed. Clinical course was uneventful on day 1 and day 2 of life. On day 3, there were acute symptoms (axillary temperature $39.9^{\circ} \mathrm{C}$ and neonatal encephalopathy) with rapid deterioration and the baby could not be revived. The NP swab collected at birth for SARS-CoV-2 was positive. Other test for reliable evidence of in-utero SARS-CoV-2 exposure, imaging, cerebrospinal fluid analysis, postmortem autopsy, or sampling(s) could not be done due to lack of consent (Table 2-Case no. 1). The other baby boy was preterm 29 weeks with birth weight $1140 \mathrm{~g}$ born to mother with asymptomatic SARS-CoV-2 infection but having gestational and intranatal risk factors including gestational diabetes, oligohydramnios, prelabor rupture of membranes, and intrauterine fetal distress. His NP swab collected at birth was negative for SARS-CoV-2. Sepsis screen was positive and blood culture was sterile. This baby had been on mechanical ventilation since birth after suffering severe perinatal asphyxia (Apgar score 1,3) and could not sustain life beyond $8 \mathrm{~h}$ of life.

Both neonates with late postnatal exposure to SARSCoV-2 were asymptomatic at the time of admission and remained so during hospital stay.

\section{Acceptance of breastfeeding}

Overall, 98\% (149/152) neonates were breastfed. Exclusive (and direct) breastfeeding was done in 67\% (102/152) neonates. Another 31\% (47/152) neonates were partial/mixed breastfed. Most common reason for partial breastfeeding was temporary mother-infant isolation among neonates admitted to NICU where they were fed with EBM as well as formula milk whenever EBM provided was not adequate. There were only three neonates who were never breastfed, one who did not get opportunity to receive any milk due to being on ventilator since birth and demise within few hours of birth and the other two who were replacement-fed (only formula milk fed) as their mothers refused to feed them with any breast milk. No mother-infant separation was done among these two replacement-fed babies.

\section{Results and interpretation of SARS-CoV-2 testing in neonates}

Total 288 NP swab samples were collected for RT-PCR testing from 150 perinatal SARS-CoV-2-exposed neonates. Single NP swab testing could be done in 54 neonates, 51 neonates underwent two tests, and $\geq 3$ tests were done in 42 neonates. Three neonates could never be tested. Twenty (13.3\%) neonates tested SARS-CoV-2 RNA positive in $\geq 1$ NP swab sample(s). The interpretation of NP swab results 
Table 1 Clinical profile and outcome in perinatal SARS-CoV-2-exposed neonates

$\begin{array}{ll}\text { Morbidities/mortality } & n \\ \mathbf{N}=150 & \%\end{array}$

$($ males $=90$, females $=60)$

Preterm birth

Low birth weight

Small for gestational age (birth weight $<10^{\text {th }}$ percentile for gestational age)

Large for gestational age (birth weight $>90^{\text {th }}$ percentile for gestational age)

Meconium-stained amniotic fluid

Pathological CTG tracings (intrauterine fetal distress)

Requirement for some resuscitation measures at birth

Low Apgar score at $1 \mathrm{~min}$ of age

Low Apgar score at $5 \mathrm{~min}$ of age

Requirement of NICU care

Requirement of respiratory support

Indications for respiratory support

Morbidities

Mortality

*Multicystic kidney

${ }^{\wedge}$ Sepsis screen positive, blood culture negative-10; sepsis screen positive, blood culture positive-2

${ }^{\#}$ Hypoxic-Ischemic-Encephalopathy stage II

$$
\begin{aligned}
& <37 \text { weeks } \\
& <34 \text { weeks } \\
& <2500 \mathrm{~g} \\
& <1500 \mathrm{~g}
\end{aligned}
$$$$
34 \quad 22.7
$$$$
3 \quad 2.0
$$$$
47 \quad 31.3
$$$$
2 \quad 1.3
$$$$
\begin{array}{ll}
57 & 38.0
\end{array}
$$$$
2 \quad 1.3
$$$$
29 \quad 19.3
$$$$
24 \quad 16.0
$$$$
34 \quad 22.7
$$

Initial steps (oro-nasal suction and/or tactile stimulation) $25 \quad 16.7$

$\begin{array}{lll}\text { Positive pressure ventilation (PPV) } & 8 & 5.3\end{array}$

$\begin{array}{lll}\text { PPV and chest compressions } & 0 & 0.0\end{array}$

PPV and chest compressions and medications $\quad 1 \quad 0.7$

$\begin{array}{lll}\text { Apgar score 0-7 } & 9 & 6.0\end{array}$

Apgar score 0-3 $\quad 4 \quad 2.7$

$\begin{array}{lll}\text { Apgar score 0-7 } & 4 & 2.7\end{array}$

Apgar score 0-3 $\quad 1 \quad 0.7$

$\begin{array}{lrr}\text { Total } & 18 & 12.0\end{array}$

Low-flow oxygen therapy $\quad 13 \quad 8.7$

Non-invasive ventilation $\quad 3 \quad 2.0$

$\begin{array}{lll}\text { Invasive ventilation } & 2 & 1.3\end{array}$

$\begin{array}{lll}\text { Postresuscitation care (perinatal asphyxia) } & 9 & 6.0\end{array}$

$\begin{array}{lll}\text { Transient tachypnea of newborn } & 4 & 2.7\end{array}$

$\begin{array}{lll}\text { Prematurity } & 3 & 2.0\end{array}$

Pneumonia (early onset sepsis) $\quad 5 \quad 3.3$

$\begin{array}{lll}\text { Hyperpyrexia and encephalopathy } & 1 & 0.7\end{array}$

Congenital anomalies $\quad 1^{*} 0.7$

Early onset sepsis $\quad 12^{\wedge} 8.0$

$\begin{array}{lll}\text { Late onset sepsis } & 0 & 0.0\end{array}$

$\begin{array}{lll}\text { Perinatal asphyxia } & 9 & 6.0\end{array}$

$\begin{array}{lll}\text { Neonatal hyperbilirubinemia } & 17 & 11.3\end{array}$

Neonatal seizures $\quad 1^{\#} \quad 0.7$

$\begin{array}{lll}\text { Moderate/severe thrombocytopenia } & 3 & 2.0\end{array}$

$\begin{array}{lll}\text { Coagulopathy } & 1 & 0.7\end{array}$

$\begin{array}{lll}\text { Shock (requiring ionotropic support) } & 1 & 0.7\end{array}$

$\begin{array}{lll}\text { Hypoglycemia } & 1 & 0.7\end{array}$

$\begin{array}{lll}\text { Hyperkalemia } & 1 & 0.7\end{array}$

$\begin{array}{lll}\text { Hyponatremia } & 1 & 0.7\end{array}$

$\begin{array}{lll}\text { Hypernatremia } & 1 & 0.7\end{array}$ 


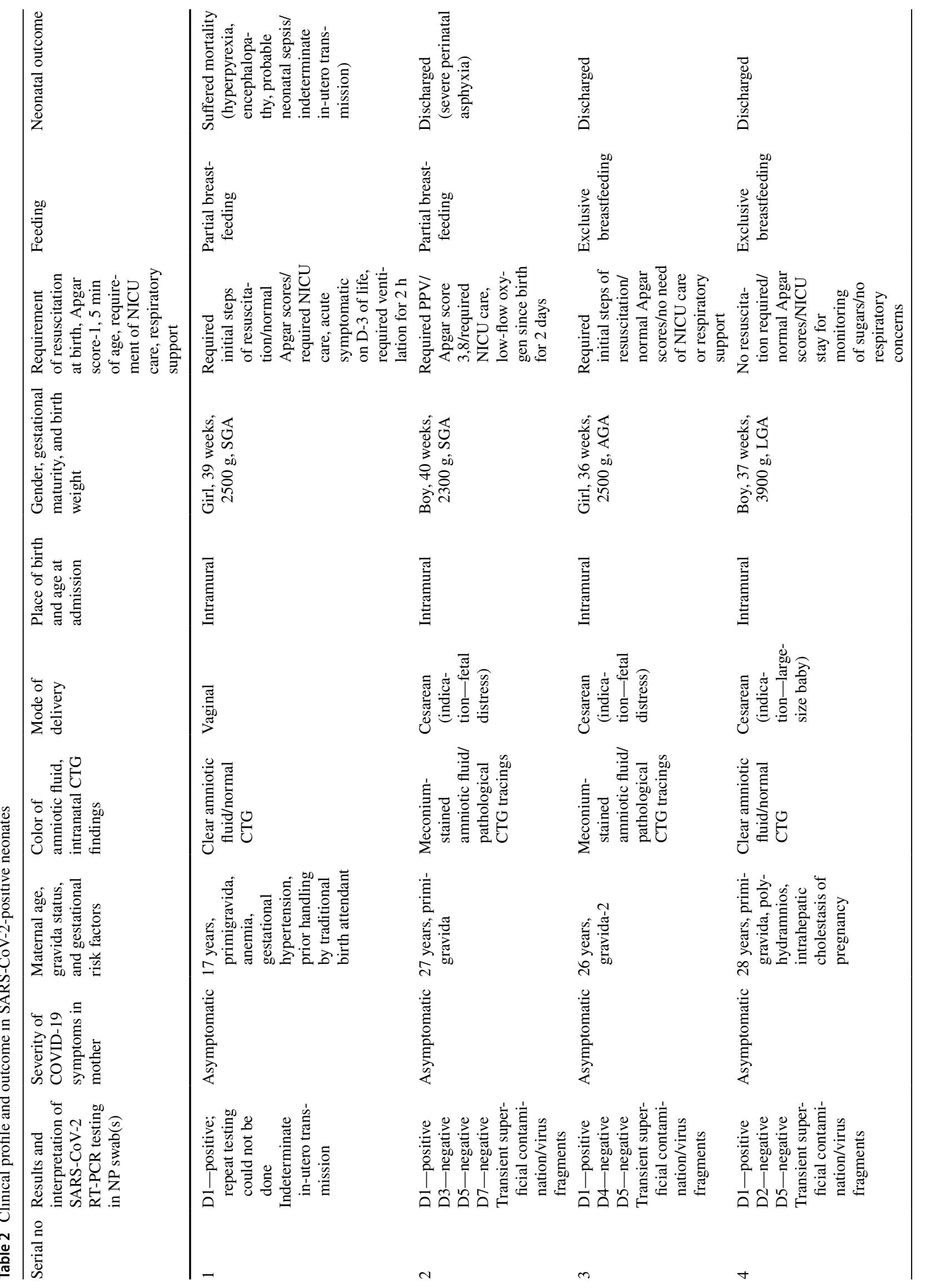




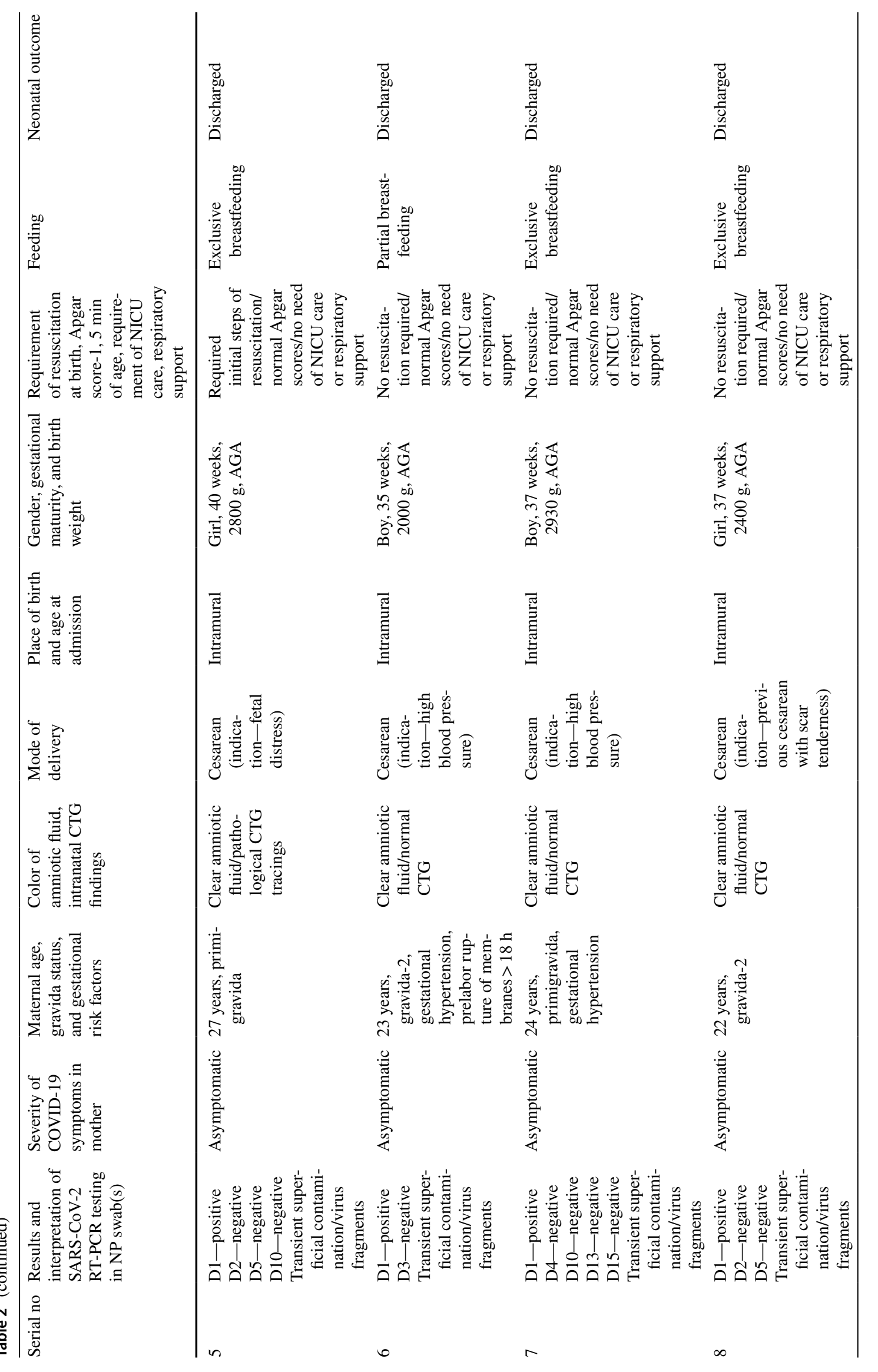














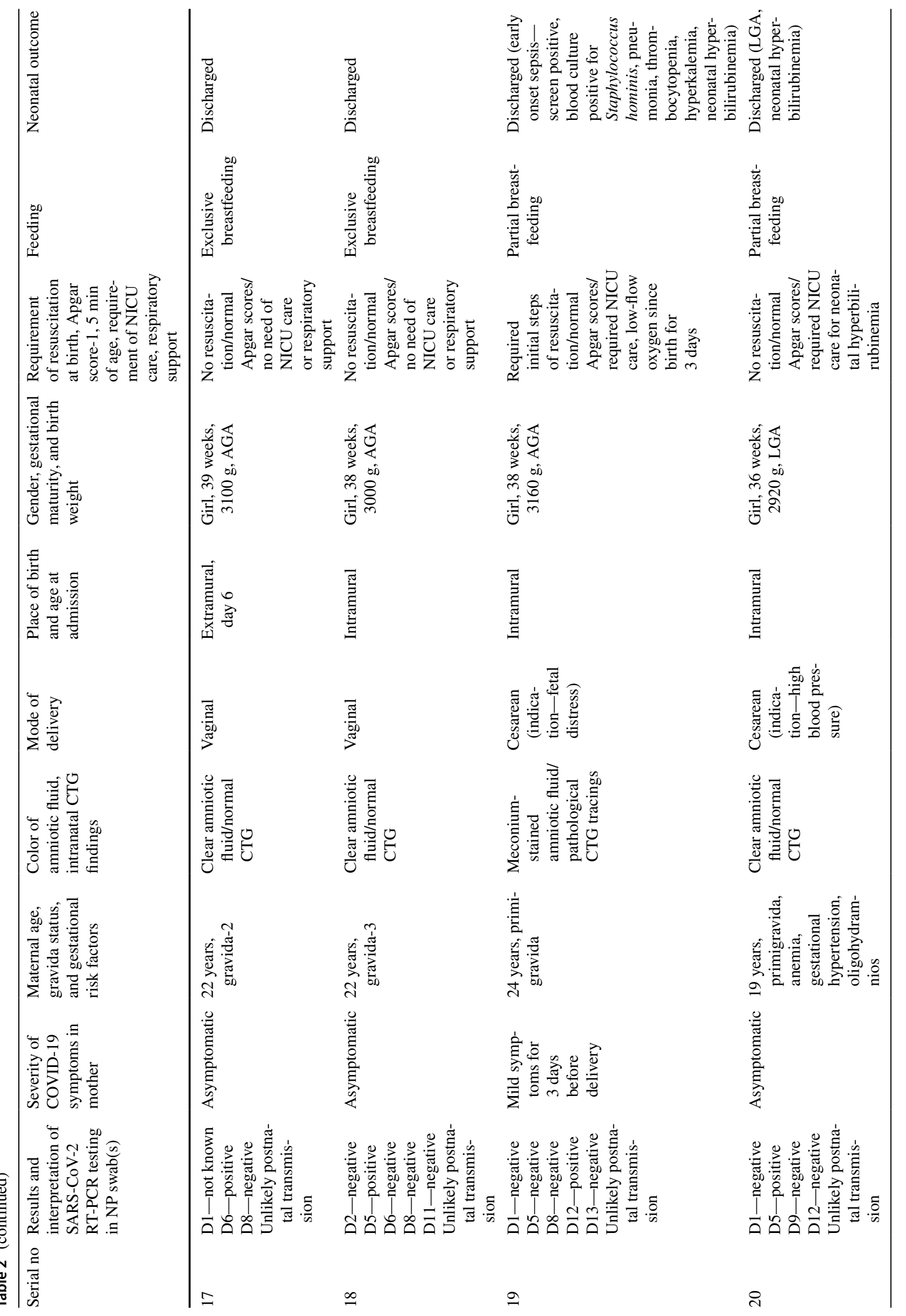


Neonates with positive SARS-CoV-2 RT-PCR in $\geq 1$ NP swab(s) collected between age 0-14 days: $\mathbf{n}$ - 20

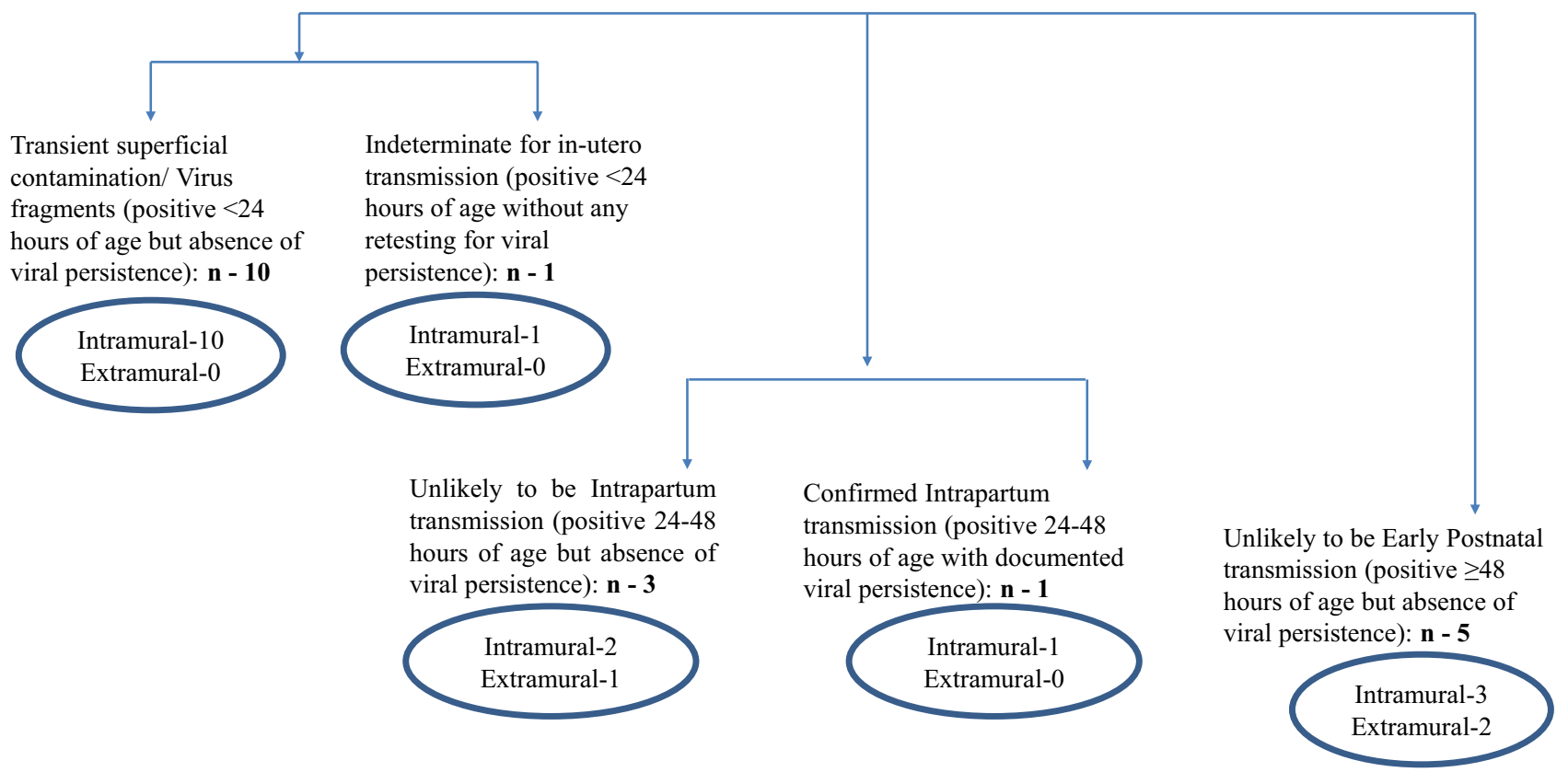

Fig. 2 Interpretation of SARS-CoV-2 RT-PCR in nasopharyngeal swab samples

using the classification scheme proposed by World Health Organization (WHO) [10] is provided in Table 2 and Fig. 2.

Eleven neonates were RT-PCR positive in NP swab sample collected $<24 \mathrm{~h}$ of age among which 10 were negative on repeat testing on day 2 . These 10 neonates without viral persistence were categorized as transient superficial contamination or virus fragments. No retesting could be done in one neonate, categorized as indeterminate for in-utero transmission (Table 2-Case no. 1). Four neonates were positive in NP swab collected on day 2 . Three did not document viral persistence at age $>48-7$ days and unlikely to be intrapartum transmission and the one who documented viral persistence in NP swabs (days 6, 10, and 12) was categorized as confirmed intrapartum SARS-CoV-2 transmission. Total 5 neonates were positive in NP swabs collected $\geq 48 \mathrm{~h}$ of age ( 3 on day 5,1 on day 6 , and 1 on day 12 of life). All were negative on retesting, unlikely to be early postnatal transmission (Fig. 2).

One neonate with late postnatal SARS-CoV-2 exposure was tested once on day 6 of exposure and the other neonate with late postnatal SARS-CoV-2 exposure was tested twice on day 7 and day 10 of exposure. All NP swab results were negative in this sub-group (Fig. 1).

\section{Clinical outcome in SARS-CoV-2-positive neonates}

The clinical details of 20 neonates who tested positive for SARS-CoV-2 RNA in $\geq 1$ NP swab sample(s) are provided in Table 2. Among them, 14 (70\%) were asymptomatic.
Respiratory symptoms were most common among the symptomatic ones (Table 2).

\section{Duration of hospital stay and telephonic follow-up}

The duration of hospital stay in SARS-CoV-2-exposed neonates ranged from $8 \mathrm{~h}$ to 32 days (mean $\pm \mathrm{SD}, 5.49 \pm 3.92$ ) guided by many factors such as the gestational maturity at birth, weight, clinical course, and the results of SARSCoV-2 testing. All 148 perinatal exposed neonates who survived early neonatal period fared well by 1 month of age without any new symptoms or concerns after discharge. Both neonates with late postnatal exposure had an asymptomatic clinical course throughout 1-month postexposure time period.

\section{Discussion}

Worldwide published literature describes a high incidence of operative delivery, preterm birth, low birth weight, intrauterine fetal distress, perinatal asphyxia, and NICU admission rates among neonates born to SARS-CoV-2-infected mothers [12-29]. The present study confirms these findings in our region although a high prevalence of gestational risk factors among SARS-CoV-2-infected mothers could be comodifying the neonatal outcome. NICU care was required by $24 \%$ neonates, and $12 \%$ neonates required respiratory support. These data are relevant as an approximate guide to 
plan and channelize resources for dedicated isolation-NICUs amidst ongoing COVID-19 pandemic.

Most of the reports describe SARS-CoV-2 infection and vertical transmission in neonates based on single positive RTPCR in upper respiratory sample. A simple approach is to classify neonatal SARS-CoV-2 infection as perinatal transmission (which includes intrauterine and intrapartum transmission) if there is a positive RT-PCR in NP swab $\leq 72 \mathrm{~h}$ after birth, and horizontal transmission if there is a negative RT-PCR $\leq 72 \mathrm{~h}$ after birth subsequently testing positive any time $>72 \mathrm{~h}$ of age $[9,11]$. Neonatology Forum India COVID-19 Registry group [11] described $8.4 \%$ risk of perinatal SARS-CoV-2 transmission and 3.1\% risk of horizontal transmission among neonates born to SARS-CoV-2-infected mothers. The risk of horizontal transmission was higher (22.1\%) among extramural neonates. Applying this approach on the data from present study, perinatal SARS-CoV-2 transmission was present in $15(10 \%)$ neonates and horizontal transmission in $5(3.3 \%)$ neonates. However, these estimates based on single positive upper respiratory (non-sterile) sample may over-estimate the true risk of vertical transmission.

Classification systems to define the timing of vertical mother-to-child SARS-CoV-2 transmission have been proposed by few groups of authors and also by the WHO [10, $30,31]$ which are elaborate and difficult to implement in daily clinical practice but useful from epidemiological point of view. The WHO classification scheme [10] guides that for confirmation of in-utero SARS-CoV-2 transmission, positive RT-PCR in sterile specimen(s) like the amniotic fluid sample collected with sterile technique during cesarean section prior to the rupture of membranes or amniocentesis, neonatal blood (not cord blood), lower respiratory tract specimens, or cerebrospinal fluid collected $<24 \mathrm{~h}$ of age with documentation of viral persistence in repeat sterile sample(s) taken at age $24-48 \mathrm{~h}$ is required. Such an evaluation to confirm in-utero transmission could not be done in the present study, and thus, in-utero transmission could not be confirmed in the neonate who was SARS-CoV-2 positive in NP swab sample collected at birth and suffered mortality. In the absence of repeat NP swab testing, this neonate was categorized as indeterminate for in-utero transmission. The non-specific sign and symptoms of varying severity tend to overlap with other non-infective and infective illnesses of newborn [32-42]. Clinical symptoms and signs are not included in the WHO classification system [10].

Neonates with positive RT-PCR in non-sterile samples (upper respiratory tract sample or stool) collected $<24 \mathrm{~h}$, if RT-PCR positive again $24-48 \mathrm{~h}$ of age, suggest possible in-utero transmission. Otherwise, a single positive RT-PCR in upper respiratory sample $<24 \mathrm{~h}$ of age could even be virus fragments acquired during passage through the birth canal or transient superficial contamination not resulting in actual infection [10]. This has been reported that around 1.6-5.2\% NP swabs collected $<24 \mathrm{~h}$ of age from neonates born to SARS-CoV-2-infected collected are positive $[11,17,18,43]$. In the present study also, $7.3 \%$ neonates were RT-PCR positive for SARS-CoV-2 RNA in NP sample collected $<24 \mathrm{~h}$ of age but most of them $(10 / 11)$ were negative on retesting. Non-sterile samples positive for SARS$\mathrm{CoV}-2$ at age $24-48 \mathrm{~h}$ also need confirmation with positive RT-PCR on a second non-sterile sample at age $>48 \mathrm{~h}-7$ days to consider the possibility of intrapartum transmission [10]. Four neonates RT-PCR positive on day 2 seemed to acquire the infection intrapartum but only one of them had viral persistence, confirmed as intrapartum transmission.

Salvatore et al. [29] described that all breastfed neonates born to SARS-CoV-2-positive mothers who were tested by RT-PCR in NP swab sample(s) between days 5-7 and day 14 of life were negative and no one developed symptoms of COVID-19. Reviewing the two datasets from India, around 8-10\% breastfed neonates born to SARS-CoV-2-positive mothers tested positive for SARS-CoV-2 in NP swab sample collected at age $\geq 48 \mathrm{~h}[17,18]$. Positive RT-PCR for SARS-CoV-2 in non-sterile samples at age $\geq 48 \mathrm{~h}$ also need confirmation in second non-sterile sample obtained within 10 days of first positive test to consider the possibility of early postnatal transmission [10]. In the present study, 5 (3.3\%) neonates seemed to acquire infection postnatal but in the absence of viral persistence, they represented early postnatal exposure, not transmission and true infection. This risk was more apparent among extramural (2/12-16.6\%) than intramural neonates $(3 / 138-2.2 \%)$, suggesting that the adequacy of precautions taken by mothers and their constant supervision during early neonatal period plays a role.

The present study suffers certain limitations. Reliable tests for the evidence of in-utero exposure could not be included in the study protocol, and thus, virological confirmation of inutero transmission could not be done. With an early discharge policy among stable mother-infant dyads, many neonates could not be tested beyond $48 \mathrm{~h}$ of age for early postnatal transmission. There were ethical concerns, also reluctance of the family to bring back a well-baby for follow-up and testing during restricted travel conditions. With few recorded outcomes, subgroup analyses to identify risk factors could not be done.

Despite these limitations, the study affirms some important findings. Among neonates born to SARS-CoV-2-positive mothers, one may be tempted to consider a positive RT-PCR in upper respiratory sample as evidence of vertical transmission but most of these neonates do not demonstrate viral persistence. Postnatal transmission seems to be rare in breastfed infants roomed-in with their clinically stable SARS-CoV-2-infected mothers following appropriate respiratory and hand hygiene practices and the clinical neonatal outcomes are decent when such protocols are implemented. However, one cannot exclude mother-to-child SARS-CoV-2 transmission by screening upper respiratory samples till 2 weeks of age. For example, the neonate may have been in close contact with his/her SARS-CoV-2-infected mother at day 10 and asymptomatic infected at day 19 of life. A prolonged 
systematic follow-up with serologic assessments may provide more data on mother-to-child SARS-CoV-2 transmission. Irrespective of the initial screening results, this would be safer to isolate these SARS-CoV-2-exposed neonates till 4 weeks of age to prevent accidental spread of infection.

The natural history of SARS-CoV-2 infection in neonates is still unknown, and as of now the learning experience from other congenital infections such as cytomegalovirus infection may be utilized [44, 45]. Routine follow-up for 1 month seems inadequate, and a long-term comprehensive surveillance till school age for neuromotor, intellectual, audio-visual, respiratory and cardiovascular outcomes is warranted among neonates with perinatal SARS-CoV-2 exposure.

Acknowledgements We would like to express our gratitude to the Dean of our institution, Dr. (Prof.) Asim Das for all the logistic and administrative support. We take this opportunity to thank nursing staff of our Neonatology team for the dedication and the effort they put into this unforeseen crisis situation.

Authors' contributions PG conceptualized and designed the study, coordinated, and supervised data collection. MS analyzed the data. All authors were involved in patient care, compilation of data, review of literature, drafting, and approval of final version of the manuscript.

Availability of data and material (data transparency) Anonymized patient data will be made available to the scientific community upon reasonable request retaining exclusive use until the publication of major outputs.

\section{Declarations}

Ethics approval The study was approved by the Institutional Ethics Committee vide letter number 134/A/11/16/Academics/MC/2016/159.

Consent to participate Yes.

Consent for publication Yes.

Conflict of interest The authors declare no competing interests.

\section{References}

1. Costa S, Posteraro B, Marchetti S, Tamburrini E, Carducci B, Lanzone A et al (2020) Excretion of SARS-CoV-2 in human breast milk. Clin Microbiol Infect 26:1430-1432. https://doi.org/10.1016/j.cmi.2020. 05.027

2. Chambers C, Krogstad P, Bertrand K, Contreras D, Tobin NH, Bode L et al (2020) Evaluation for SARS-CoV-2 in breast milk from 18 infected women. JAMA 324:1347-1348. https://doi.org/ 10.1001/jama.2020.15580

3. Centeno-Tablante E, Medina-Rivera M, Finkelstein JL, Rayco-Solon P, Garcia-Casal MN, Rogers L et al (2021) Transmission of SARS-CoV-2 through breast milk and breastfeeding: a living systematic review. Ann N Y Acad Sci 1484:32-54. https://doi.org/10.1111/nyas.14477

4. Krogstad P, Contreras D, Ng H, Tobin N, Chambers CD, Bertrand $\mathrm{K}$, et al. (2021) No evidence of infectious SARS-CoV-2 in human milk: analysis of a cohort of 110 lactating women. medRxiv: 2021.04.05.21254897. https://doi.org/10.1101/2021.04.05.21254897
5. Pace RM, Williams JE, Järvinen KM, Belfort MB, Pace CD, Lackey KA, et al. (2020) COVID-19 and human milk: SARS-CoV-2, antibodies, and neutralizing capacity. medRxiv: 2020.09.16.20196071. https://doi.org/10.1101/2020.09.16.20196071

6. Demers-Mathieu V, DaPra C, Mathijssen G, Sela A, D, M Jarvinen K, Seppo A, et al (2021) Human milk antibodies against S1 and S2 subunits from SARS-CoV-2, HCoV-OC43, and HCoV-229E in mothers with a confirmed COVID-19 PCR, viral symptoms, and unexposed mothers. Int J Mol Sci 22:1749. https://doi.org/ 10.3390/ijms22041749

7. Yeo KT, Oei JL, De Luca D, Schmölzer GM, Guaran R, Palasanthiran $P$ et al (2020) Review of guidelines and recommendations from 17 countries highlights the challenges that clinicians face caring for neonates born to mothers with COVID-19. Acta Paediatr 109:2192-2207. https://doi.org/10.1111/apa.15495

8. Chawla D, Chirla D, Dalwai S, Deorari AK, Ganatra A, Gandhi A et al (2020) Federation of Obstetric and Gynaecological Societies of India (FOGSI), National Neonatology Forum of India (NNF) and Indian Academy of Pediatrics (IAP). Perinatal-Neonatal Management of COVID-19 Infection - Guidelines of the Federation of Obstetric and Gynaecological Societies of India (FOGSI), National Neonatology Forum of India (NNF), and Indian Academy of Pediatrics (IAP). Indian Pediatr 57:536-548. https://doi.org/10.1007/ s13312-020-1852-4

9. Clinical practice guideline: perinatal-neonatal management of COVID-19. Version 3.0: updated 16 June 2021. National Neonatology Forum, India, Federation of Obstetric \& Gynaecological Societies of India \& Indian Academy of Pediatrics. https://www. fogsi.org/wp-content/uploads/gcpr/perinatal-neonatal-managementof-covid-19.pdf. Accessed 18 June 2021

10. World Health Organization (2021) Definition and categorization of the timing of mother-to-child transmission of SARS-CoV-2. https:// www.who.int/publications/i/item/WHO-2019-nCoV-mother-tochild-transmission-2021.1. Accessed 28 May 2021

11. National Neonatology Forum (NNF) COVID-19 Registry Group (2021) Outcomes of neonates born to mothers with coronavirus disease 2019 (COVID-19)- National Neonatology Forum (NNF) India COVID-19 Registry. Indian Pediatr: S097475591600300. Epub ahead of print

12. Liu Y, Chen H, Tang K, Guo Y (2020) Clinical manifestations and outcome of SARS-CoV-2 infection during pregnancy. J Infect. Epub ahead of print. doi: S0163-4453(20)30109-2

13. Chen R, Zhang Y, Huang L, Cheng BH, Xia ZY, Meng QT (2020) Safety and efficacy of different anesthetic regimens for parturients with COVID-19 undergoing cesarean delivery: a case series of 17 patients. Can J Anaesth 67:655-663. https://doi.org/10.1007/ s12630-020-01630-7

14. Khan S, Jun L, Nawsherwan SR, Li Y, Han G et al (2020) Association of COVID-19 with pregnancy outcomes in health-care workers and general women. Clin Microbiol Infect 26:788-790. https://doi.org/10.1016/j.cmi.2020.03.034

15. Chen L, Li Q, Zheng D, Jiang H, Wei Y, Zou L et al (2020) Clinical characteristics of pregnant women with Covid-19 in Wuhan. China N Engl J Med 382:e100. https://doi.org/10.1056/NEJMc2009226

16. Yan J, Guo J, Fan C, Juan J, Yu X, Li J et al (2020) Coronavirus disease 2019 in pregnant women: a report based on 116 cases. Am J Obstet Gynecol 223:111.e1-111.e14. https://doi.org/10.1016/j. ajog.2020.04.014

17. Nanavati R, Mascarenhas D, Goyal M, Haribalakrishna A, Nataraj G (2021) A single-center observational study on clinical features and outcomes of 21 SARS-CoV-2-infected neonates from India. Eur J Pediatr 180:1895-1906. https://doi.org/10.1007/ s00431-021-03967-7

18. Anand P, Yadav A, Debata P, Bachani S, Gupta N, Gera R (2021) Clinical profile, viral load, management and outcome of neonates born to COVID 19 positive mothers: a tertiary care centre 
experience from India. Eur J Pediatr 180:547-559. https://doi.org/ 10.1007/s00431-020-03800-7

19. Zimmermann P, Curtis N (2020) COVID-19 in children, pregnancy and neonates: a review of epidemiologic and clinical features. Pediatr Infect Dis J 39:469-477. https://doi.org/10.1097/ INF.0000000000002700

20. Huntley BJF, Huntley ES, Di Mascio D, Chen T, Berghella V, Chauhan SP (2020) Rates of maternal and perinatal mortality and vertical transmission in pregnancies complicated by severe acute respiratory syndrome coronavirus 2 (SARS-Co-V-2) infection: a systematic review. Obstet Gynecol 136:303-312. https://doi.org/ 10.1097/AOG.0000000000004010

21. Rodrigues C, Baía I, Domingues R, Barros H (2020) Pregnancy and breastfeeding during COVID-19 pandemic: a systematic review of published pregnancy cases. Front Public Health 8:558144. https://doi.org/10.3389/fpubh.2020.558144

22. Duran P, Berman S, Niermeyer S, Jaenisch T, Forster T, Ponce G, de Leon R et al (2020) COVID-19 and newborn health: systematic review. Rev Panam Salud Publica 44:e54. https://doi.org/10. 26633/RPSP.2020.54

23. Zaigham M, Andersson O (2020) Maternal and perinatal outcomes with COVID-19: a systematic review of 108 pregnancies. Acta Obstet Gynecol Scand 99:823-829. https://doi.org/10.1111/ aogs. 13867

24. Juan J, Gil MM, Rong Z, Zhang Y, Yang H, Poon LC (2020) Effect of coronavirus disease 2019 (COVID-19) on maternal, perinatal and neonatal outcome: systematic review. Ultrasound Obstet Gynecol 56:15-27. https://doi.org/10.1002/uog.22088

25. Smith V, Seo D, Warty R, Payne O, Salih M, Chin KL et al (2020) Maternal and neonatal outcomes associated with COVID-19 infection: a systematic review. PLoS One 15:e0234187. https:// doi.org/10.1371/journal.pone.0234187.

26. Villar J, Ariff S, Gunier RB, Thiruvengadam R, Rauch S, Kholin A, et al. (2021) Maternal and neonatal morbidity and mortality among pregnant women with and without COVID-19 infection: the INTERCOVID Multinational Cohort Study. JAMA Pediatr: e211050. https://doi.org/10.1001/jamapediatrics.2021.1050

27. Mullins E, Hudak ML, Banerjee J, Getzlaff T, Townson J, Barnette $\mathrm{K}$ et al (2021) PAN-COVID investigators and the National Perinatal COVID-19 Registry Study Group. Pregnancy and neonatal outcomes of COVID-19: coreporting of common outcomes from PAN-COVID and AAP-SONPM registries. Ultrasound Obstet Gynecol 57:573-581. https://doi.org/10.1002/uog.23619

28. Woodworth KR, Olsen EO, Neelam V, Lewis EL, Galang RR, Oduyebo $T$ et al (2020) CDC COVID-19 Response Pregnancy and Infant Linked Outcomes Team; COVID-19 Pregnancy and Infant Linked Outcomes Team (PILOT). Birth and infant outcomes following laboratory-confirmed SARS-CoV-2 infection in pregnancy - SET-NET, 16 Jurisdictions, March 29-October 14, 2020. MMWR Morb Mortal Wkly Rep 69:1635-1640. https:// doi.org/10.15585/mmwr.mm6944e2

29. Salvatore CM, Han JY, Acker KP, Tiwari P, Jin J, Brandler M et al (2020) Neonatal management and outcomes during the COVID19 pandemic: an observation cohort study. Lancet Child Adolesc Health 4:721-727. https://doi.org/10.1016/S2352-4642(20) 30235-2

30. Shah PS, Diambomba Y, Acharya G, Morris SK, Bitnun A (2020) Classification system and case definition for SARS-CoV-2 infection in pregnant women, fetuses, and neonates. Acta Obstet Gynecol Scand 99:565-568. https://doi.org/10.1111/aogs.13870

31. Blumberg DA, Underwood MA, Hedriana HL, Lakshminrusimha S (2020) Vertical transmission of SARS-CoV-2: what is the optimal definition? Am J Perinatol 37:769-772. https://doi.org/10. $1055 / \mathrm{s}-0040-1712457$
32. Zeng L, Xia S, Yuan W, Yan K, Xiao F, Shao J et al (2020) Neonatal early-onset infection with SARS-CoV-2 in 33 neonates born to mothers with COVID-19 in Wuhan, China. JAMA Pediatr 174:722-725. https://doi.org/10.1001/jamapediatrics.2020.0878

33. Kamali Aghdam M, Jafari N, Eftekhari K (2020) Novel coronavirus in a 15-day-old neonate with clinical signs of sepsis, a case report. Infect Dis (Lond) 52:427-429. https://doi.org/10.1080/ 23744235.2020.1747634

34. Sinelli M, Paterlini G, Citterio M, Di Marco A, Fedeli T, Ventura ML (2020) Early neonatal SARS-CoV-2 infection manifesting with hypoxemia requiring respiratory support. Pediatrics 146:e20201121. https://doi.org/10.1542/peds.2020-1121

35. Chacón-Aguilar R, Osorio-Cámara JM, Sanjurjo-Jimenez I, González-González C, López-Carnero J, Pérez-Moneo B (2020) COVID-19: fever syndrome and neurological symptoms in a neonate. An Pediatr (Engl Ed) 92:373-374. https://doi.org/10.1016/j. anpede.2020.04.001

36. Gale C, Quigley MA, Placzek A, Knight M, Ladhani S, Draper ES et al (2021) Characteristics and outcomes of neonatal SARSCoV-2 infection in the UK: a prospective national cohort study using active surveillance. Lancet Child Adolesc Health 5:113121. https://doi.org/10.1016/S2352-4642(20)30342-4

37. De Bernardo G, Giordano M, Zollo G, Chiatto F, Sordino D, De Santis R et al (2020) The clinical course of SARS-CoV-2 positive neonates. J Perinatol 40:1462-1469. https://doi.org/10.1038/ s41372-020-0715-0

38. De Rose DU, Piersigilli F, Ronchetti MP, Santisi A, Bersani I, Dotta A et al (2020) (2020) Novel coronavirus disease (COVID19) in newborns and infants: what we know so far. Ital J Pediatr 46:56. https://doi.org/10.1186/s13052-020-0820-x

39. Dhir SK, Kumar J, Meena J, Kumar P (2020) Clinical features and outcome of SARS-CoV-2 infection in neonates: a systematic review. J Trop Pediatr: fmaa059. https://doi.org/10.1093/tropej/ fmaa059

40. Dumpa V, Kamity R, Vinci AN, Noyola E, Noor A (2020) Neonatal coronavirus 2019 (COVID-19) infection: a case report and review of literature. Cureus 12:e8165. https://doi.org/10.7759/ cureus. 8165

41. Gordon M, Kagalwala T, Rezk K, Rawlingson C, Ahmed MI, Guleri A (2020) Rapid systematic review of neonatal COVID-19 including a case of presumed vertical transmission. BMJ Paediatrics Open 4:e000718. https://doi.org/10.1136/bmjpo-2020-000718

42. Raschetti R, Vivanti AJ, Vauloup-Fellous C, Loi B, Benachi A, De Luca D (2020) Synthesis and systematic review of reported neonatal SARS-CoV-2 infections. Nat Commun 11:5164. https:// doi.org/10.1038/s41467-020-18982-9

43. Knight M, Bunch K, Vousden N, Morris E, Simpson N, Gale C, et al. (2020) UK Obstetric Surveillance System SARS-CoV-2 Infection in Pregnancy Collaborative Group. Characteristics and outcomes of pregnant women admitted to hospital with confirmed SARS-CoV-2 infection in UK: national population based cohort study. BMJ 369: m2107. https://doi.org/10.1136/bmj.m2107

44. Ronchi A, Zeray F, Lee LE, Owen KE, Shoup AG, Garcia F et al (2020) Evaluation of clinically asymptomatic high risk infants with congenital cytomegalovirus infection. J Perinatol 40:89-96. https://doi.org/10.1038/s41372-019-0501-z

45. Marsico C, Kimberlin DW (2017) Congenital cytomegalovirus infection: advances and challenges in diagnosis, prevention and treatment. Ital J Pediatr 43:38. https://doi.org/10.1186/ s13052-017-0358-8

Publisher's Note Springer Nature remains neutral with regard to jurisdictional claims in published maps and institutional affiliations. 


\section{Authors and Affiliations}

\section{Priyanka Gupta ${ }^{1}$ (D) Vijay Pratap Khatana ${ }^{1} \cdot$ Rashmie Prabha $^{1} \cdot$ Inderkant Jha ${ }^{1} \cdot$ Mitasha Singh $^{2}$.} Anil Kumar Pandey ${ }^{3}$. Ashima Kesri ${ }^{4}$

Vijay Pratap Khatana

khatanavijaypratap6288@gmail.com

Rashmie Prabha

rashmie92@gmail.com

Inderkant Jha

dr.inderkantjha07@gmail.com

Mitasha Singh

mitasha.17@gmail.com

Anil Kumar Pandey

drpandey.ak@yahoo.co.in

Ashima Kesri

arora.ashima88@gmail.com
Department of Pediatrics and Neonatology, ESIC Medical College and Hospital, NIT-3, Faridabad, Haryana, India 121001

2 Department of Community Medicine, ESIC Medical College and Hospital, NIT-3, Faridabad, Haryana, India 121001

3 Department of Molecular Biology Laboratory, ESIC Medical College and Hospital, NIT-3, Faridabad, Haryana, India 121001

4 Department of Obstetrics and Gynecology, ESIC Medical College and Hospital, NIT-3, Faridabad, Haryana, India 121001 